\title{
Personality and Sociality in Captive Tigers (Panthera tigris)
}

\author{
Giovanni Quintavalle Pastorino ${ }^{1,2}$, Federica Paini ${ }^{1}$, Carys Louisa Williams ${ }^{3}$, \\ Massimo Faustini ${ }^{1}$ and Silvia Michela Mazzola ${ }^{1 *}$ \\ ${ }^{1}$ Department of Veterinary Medicine, Università degli Studi di Milano, Milan, Italy. \\ ${ }^{2}$ Faculty of Life Sciences, The University of Manchester, Oxford Road, Manchester, M13 9PT, \\ United Kingdom \\ ${ }^{3}$ Institute of Zoology, Zoological Society of London, Regents Park, London, NW1 4RY,
United Kingdom.
}

\section{Authors' contributions}

This work was carried out in collaboration between all authors. Authors GQP and SMM designed the study, wrote the protocol and managed the literature searches, author FP collected the data of behavioral observations, author MF performed the statistical analysis, authors SMM and CLW wrote the first draft of the manuscript. All authors read and approved the final

manuscript.

\section{Article Information}

DOI: $10.9734 / A R R B / 2017 / 38122$

Editor(s):

(1) George Perry, Dean and Professor of Biology, University of Texas at San Antonio, USA.

Reviewers:

(1) Robin Cook, University of the Witwatersrand, South Africa. (2) Otolorin, Gbeminiyi Richard, Ahmadu Bello University, Nigeria. (3) Arbab Sikandar Sikandar, University of Veterinary and Animal Sciences, Pakistan. Complete Peer review History: http://www.sciencedomain.org/review-history/22359

Original Research Article

Received $13^{\text {th }}$ November 2017 Accepted 14 ${ }^{\text {th }}$ December 2017 Published $19^{\text {th }}$ December 2017

\section{ABSTRACT}

Aims: In this study we assessed the personality and sociality of eight zoo tigers.

Place and Duration of the Study: This study was conducted over five months at Le Cornelle Faunistic Park (Valbrembo, BG, Italy).

Methodology: A multifaceted approach of observer ratings (rating method) and keeper questionnaires (coding method) was used to produce personality profiles for each tiger. Focal animal behavioural observations allowed the production of time budgets and enclosure usage for each animal. Sociality was measured through Association Index, both for intraspecific (tiger-tiger) 
and interspecific (keeper-tiger) dyads. Keeper Association Index and eventual tiger affiliative behavior towards keepers was measured during indoor interactions in the morning and in the evening at lock up and feeding times.

Results: All the results outlined a distinct personality in each animal, different levels of intraspecific sociality and affiliative behavior towards each keeper.

Conclusions: We advocate that this deeper understanding of each animal's personality and behavior can offer practical help to zoological institutions to facilitate daily husbandry, animal welfare, tailor training or enrichment and ultimately increase reproductive success.

Keywords: Tiger; Panthera tigris; personality; animal welfare.

\section{INTRODUCTION}

Psychologists describe personality as "psychological qualities that contribute to an individual's enduring and distinctive patterns of feeling, thinking, and behaving" [1]. The field of animal personality research has seen a great boost in recent years, thanks to the remarkable implications in the ecology and evolution of animal behaviours [2]. Inter-individual variation, which was once considered background "noise" in behavioural ecological studies, can now be formally attributed to individual differences, which persist through time [3].

Practical applications of personality research in captive animals include husbandry, training and breeding programs. Personality assessment may facilitate individual-based management, which may help to maximize the welfare and overall success of a captive collection [4,5]. Chadwick [6] found that personality assessments of cheetahs (Acinonyx jubatus) helped zoos organize successful breeding groups since pairs with more divergent personalities had greater breeding success. Improved breeding success enhances welfare by decreasing the need for relocating animals because a mismatched pair had low reproductive success. Prior to introducing an animal to a captive collection, personality assessment can help to determine how the new individual will affect group dynamics [7] and whether any particular mitigation measures might be required in order to increase success.

Methods recently formalized and adapted [8] have allowed the demonstration that personality can be detected across a wide spectrum of animal species $[9,10]$. One reliable method to evaluate personality is behavioral coding, where objective data is collected during behavioral observations, either under normal circumstances or in response to specific tests $[4,11,12,13,14,15]$.
Other tools used in behavioral studies may also be helpful to delineate personality traits. Among them, the sociogram (described by Rees [16] and applied by Cinková and Bičík [17] in rhinos, and by Chadwick [6] in cheetahs) is a social network diagram that demonstrates the strength of the relationship between two individuals. The composite sociality index (CSI), used by Micheletta [18] and by Pullen [19] respectively in macaques and gorillas, is a factor that highlights social relationships and the spread of participation index (SPI), developed by Dickens [20] and adapted by Plowman [21], produces a value which indicates evenness of enclosure use, even when enclosure zones are of different size.

Big cats in zoos are difficult to study in terms of obtaining a large sample size and coordinating across zoos. In a study conducted by Gartner and Weiss on snow leopards [5] twenty personality traits were quantified using visual scales, based on those used by Wielebnowski [22]. Chadwick [6] proposed a longer questionnaire to evaluate each cheetah's personality. In the current study, adaptations of these methods will be applied in order to delineate personality profiles in tiger.

With the goal of implementing the data useful to the formation of a personality profile of the subject, in the present study we have chosen to also consider the interactions between keeper and animals.

Interactions that animals experience can have a significant influence on their health and welfare. These interactions can occur between animals themselves, but also between animals and humans ( $\mathrm{HAl})$, and their establishment could be deeply influenced by the personality of the individual involved [5,23]. Humans and animals come into contact with each other in a variety of settings, and wherever there is contact there is the opportunity for interaction to take place. 
Interaction with companion animals is well known, but HAl also occurs in zoos [24] and even the wild [25]. Repeated interactions between the same animals and humans can lead to the development of a longer-term relationship between the two. Human-animal relationships (HARs) are likely to develop between exotic animals and their keepers, not only in laboratories but also in zoos [26]. Animals in zoos experience people in a different way from animals in any other situation: they are cared for by a limited number of very familiar people, but are also exposed daily to large numbers of unfamiliar visitors whose attention on the animals creates intense human-animal interactions for the animals $[27,28]$.

The aim of this study was to characterize Le Cornelle Faunistic Park's tiger personalities, using a combination of behavioural observations and observations of keeper-animal interactions. Integrating behavioural observations data with those highlighted by behavioural study tools may be useful as a complement to traditional techniques of personality assessment.

The purpose would be to set up an appropriate and standardized methodology that could be shared, enabling the comparison of personality profiles and behavioral responses to environmental stimuli across captive collections.

\section{METHODS}

\subsection{Study Area and Subjects}

All the animals enrolled were from Le Cornelle Faunistic Park, Valbrembo (BG) Italy (Latitude: N 4542.944 - Longitudine: E 9 35.804). The pride consisted of 8 tigers: 4 females and 4 males, with ages ranging from 2 to 12 years old (Table 1), housed in three distinct enclosures. The enclosure shown in Fig. 1A houses a family group, consisting of four individuals (Fig. 1, A) while the other two enclosures house two couples (Fig. 1 B, C). All the enclosures consist of an outside paddock with access to an inside area.

\subsection{Observation Data}

\section{$\underline{\text { 2.2.1 External enclosures }}$}

Observations of captive tiger pride occurred between March and July 2015.

Tigers were monitored three days a week for seven weeks, with four 80 min sessions each day, two in the morning (between 10:00-12:00) and two in the afternoon (between 14:00-16:00).

Focal animal behavioural observations using continuous sampling were completed to record the state and event behaviours for each animal [15]. Each 80 minute observation period was divided such that 10 minutes were spent observing each animal [29]. An observation session ended if the focal animal spent five consecutive minutes out of the observer's sight. Total observation time summed between observation periods was approximately 107 hours. Included in each observation period were recordings of weather (i.e., sunny, cloudy, or rainy), temperature (Weather.com, 2016), approximate crowd size, and decibel readings at five minute intervals. Individual tiger identification was facilitated by assistance from keepers during the pilot study and by use of binoculars to note specific markings on each individual.

The sessions were recorded using a Canon Legria HFR76 HD camcorder. At a later stage of the study, each video shot was analyzed in order to recheck the correct succession of the events during the behavioral observation. The behaviors were recorded based on a standardized lions ethogram [15], which was adapted for this project based on behaviors observed during a preliminary pilot study (Table 2). To create activity budgets, similar behaviors were put into classes (Table 3 ), based on groups in similar research [15].

Table 1. Members of the tigers pride at Parco Faunistico Le Cornelle

\begin{tabular}{llllll}
\hline Name & Age & Sex & Relationship & & \\
\hline Dharma & 8 & F & Mother of Kira and Sky & Hand reared & Panthera tigris white \\
Kuru & 8 & MV & Father of Kira and Sky & Hand reared & Panthera tigris white \\
Kira & 2 & F & Sister of Sky & Parent reared & Panthera tigris white stripeless \\
Sky & 2 & M & Brother of Kira & Parent reared & Panthera tigris white \\
Romeo & 6 & MV & Unrelated & Hand reared & Panthera tigris \\
Giulietta & 7 & F & Unrelated & Hand reared & Panthera tigris \\
Burma & 12 & F & Unrelated & Hand reared & Panthera tigris gold \\
Obelix & 9 & M & Unrelated & Hand reared & Panthera tigris \\
\hline
\end{tabular}



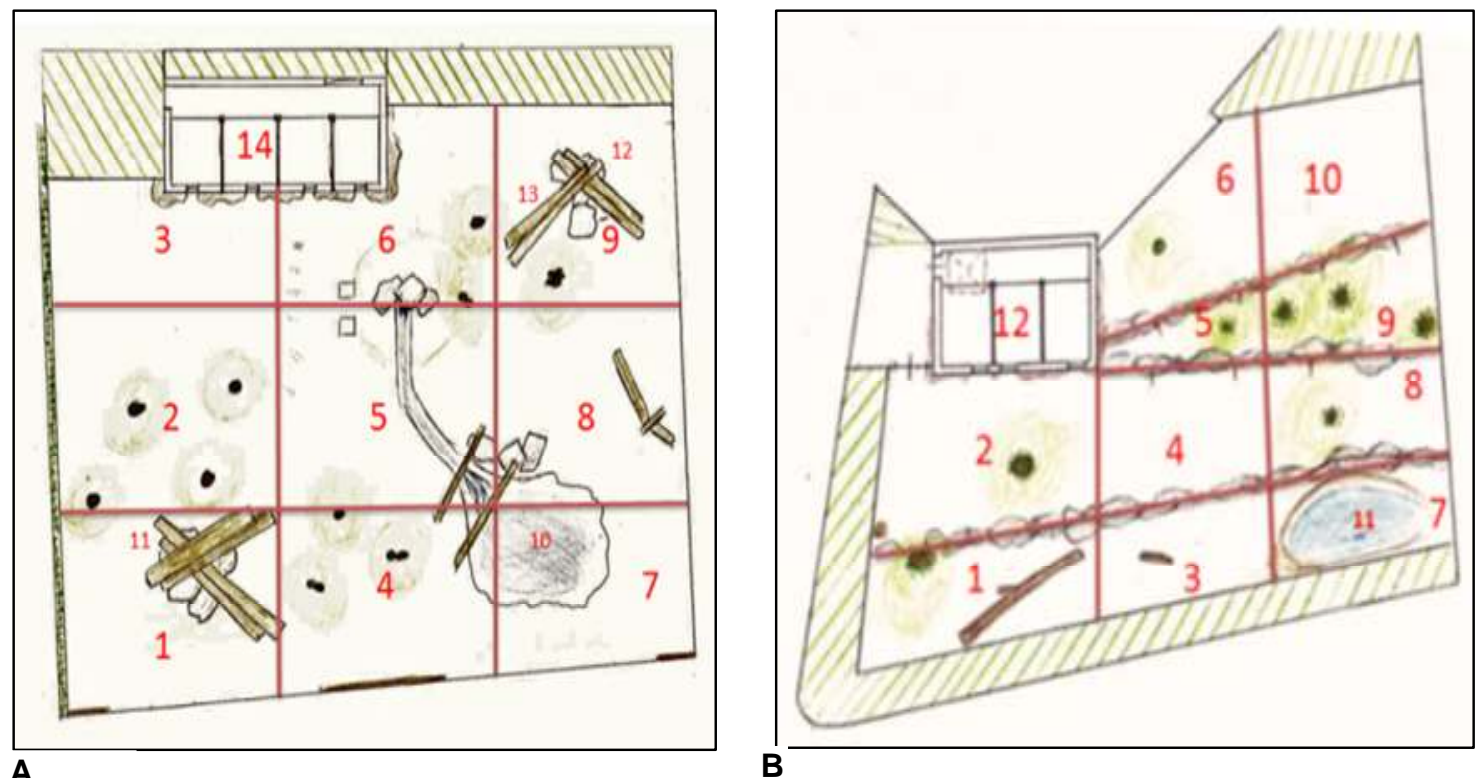

A

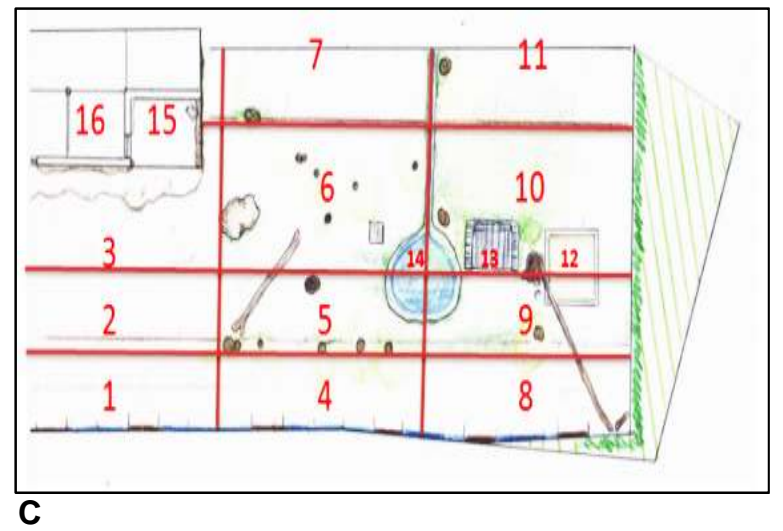

Fig. 1. Tiger enclosures.

Enclosures are arbitrarily divided into zones, in order to determine zone usage and the Spread of Participation Index (SPI).

(A) Dharma, Kuru, Kira and Sky enclosure; (B) Burma and Obelix enclosure;

(C) Romeo and Giulietta enclosure.

Table 2. Ethogram

\begin{tabular}{l}
\hline State behaviour \\
\hline Out of sight (OOS) \\
Decubitus - Dorsal (DD) \\
Decubitus - Lateral (LD) \\
Decubitus - Lateral - Legs Raised (DLLR) \\
Decubitus - Sternal (SD) \\
Sternal - Sphynx (SPH) \\
Sternal - Lunula (LUN) \\
Ears forward (EF) \\
Ears backwards (EB) \\
Facing conspecific (FC) \\
Facing observer (FO) \\
Facing public (FP)
\end{tabular}

State behaviour

ut of sight $(00$

Decubitus - Lateral (LD)

Decubitus - Lateral - Legs Raised (DLLR)

Decubitus - Sternal (SD)

Sternal - Lunula (LUN)

Ears forward (EF)

Ears backwards (EB)

Facing observer (FO)

Description
Beyond one's range of vision
Lays down on the dorsum
Lays down laterally
Lays down laterally, one back leg raised
Lays down on the sternum
Lays down on the sternum, back legs parallel and
orientated forward
Lays down on the sternum, legs put to one side
Ears oriented forward
Ears oriented backward
Stares at another animal of the same species
Stares at the observer
Stares at the public

\section{Description}

Lays down laterally

Lays down laterally, one back leg raised

ays down on the sternum

orientated forward

Lays down on the sternum, legs put to one side

Ears oriented backward

Stares at another animal of th

Stares at the public 


\begin{tabular}{|c|c|}
\hline Proximity to conspecific - body length (BL) & Within one body length of other animal \\
\hline $\begin{array}{l}\text { Proximity to conspecific - far }(\boldsymbol{F}) \\
\text { Proximity to conspecific - contact }(\boldsymbol{C})\end{array}$ & $\begin{array}{l}\text { More than one body length away from the other animal } \\
\text { In body contact with conspecific }\end{array}$ \\
\hline Sitting (SIT) & $\begin{array}{l}\text { Upright position, all four feet on ground, front legs straight, } \\
\text { back legs folded }\end{array}$ \\
\hline Standing (STA) & $\begin{array}{l}\text { Stands with all four legs extended, paws on the ground, } \\
\text { immobile }\end{array}$ \\
\hline Event Behaviour & Description \\
\hline Allogroom $(\boldsymbol{A G} \boldsymbol{X}) \times$ is the animal & Licks the fur of a conspecific \\
\hline Allogroomed $(\boldsymbol{A G D} \boldsymbol{b} \boldsymbol{X})$ & Has the fur licked by a conspecific \\
\hline Bare teeth (BAT $\boldsymbol{X}$ a) a for active & $\begin{array}{l}\text { Animal opens its mouth and pulls the lips back, exposing } \\
\text { its teeth }\end{array}$ \\
\hline $\begin{array}{l}\text { Receiving bare teeth (BAT } \boldsymbol{X} \boldsymbol{p}) \text { p for } \\
\text { passive }\end{array}$ & Is on the receiving end of bared teeth \\
\hline Bite $(\boldsymbol{B T} \boldsymbol{X})$ & Mouth closes on object or conspecific \\
\hline Bitten (BT $\boldsymbol{b} \boldsymbol{X})$ & Is bitten by conspecific \\
\hline Belly up (B UP) & $\begin{array}{l}\text { Animal lies on its back with throat and belly exposed to } \\
\text { the opponent }\end{array}$ \\
\hline Belly up defensive posture (B UP DP) & $\begin{array}{l}\text { Animal lies on its back with bared teeth, all four paws up } \\
\text { with claws unsheathed }\end{array}$ \\
\hline Chase $(\mathrm{CH} \mathrm{X})$ & Runs after conspecific or other being/object \\
\hline Chased (CHD b X) & Pursued by conspecific \\
\hline Climb up $(\mathbf{C U})$ & Ascends an object or structure \\
\hline Climb down (CD) & Descends an object or structure \\
\hline Defensive open mouth (DOM X) & Mouth wide open in defensive stance \\
\hline $\operatorname{Drink}(\boldsymbol{D R})$ & Lapps up water and swallows \\
\hline Defecate (DF) & Relieves colon, releases faeces \\
\hline Eat $(E A T)$ & Ingests food by chewing and swallowing \\
\hline Eat Grass (EAG) & Ingest grass by chewing \\
\hline Stretching (STR) & $\begin{array}{l}\text { Extend all body and forelegs forward and put the back } \\
\text { and tail up }\end{array}$ \\
\hline Fight $(\boldsymbol{F} \boldsymbol{X})$ & Assaults conspecific \\
\hline Assaulted (ASS b X) & Is assaulted by conspecific \\
\hline Jump on (JM) & $\begin{array}{l}\text { Attack suddenly and forcefully jump on the back of } \\
\text { conspecific }\end{array}$ \\
\hline Paw $(\boldsymbol{P W})$ & Strike with the paw someone else \\
\hline Flehmen (FH) & $\begin{array}{l}\text { Sniffs, then lift head with open mouth, breath in, eyes } \\
\text { almost closed and upper lip curled }\end{array}$ \\
\hline Head butt (HB X) & Briefly pushes/bumps its head against a conspecific's head \\
\hline Head butted (HB b X) & Has is head briefly bumped by a conspecific's head \\
\hline Scratch (SRT) & Damage and mark the surface of by scraping with nails \\
\hline Lick object (LO) & Protrudes tongue from the mouth and strokes object with it \\
\hline Lick lips (LL) & Protrudes tongue from the mount and lick lips \\
\hline Pace $(\boldsymbol{P C})$ & Repetitive locomotion in a fixed pattern. \\
\hline Head shake (HSH) & $\begin{array}{l}\text { Repetitive move of the head with short and quick } \\
\text { movements }\end{array}$ \\
\hline Circling (CIR) & Repetitive locomotion in a circle around \\
\hline Twitch (TW) & $\begin{array}{l}\text { Moving with a sudden, quick and short movements as } \\
\text { reaction to something/someone }\end{array}$ \\
\hline Move backwards (MB b X) & $\begin{array}{l}\text { Moving backwards with ears backwards and head down } \\
\text { as reaction to someone }\end{array}$ \\
\hline Play object (PLO) & Interacts with objects \\
\hline Play with conspecific ( $P L X$ a) & $\begin{array}{l}\text { Initiates interaction with conspecific in a non-harmful } \\
\text { manner (chasing, jumping, wrestling, etc.) and gets no } \\
\text { response }\end{array}$ \\
\hline $\begin{array}{l}\text { Play with conspecific and is reciprocated } \\
(\boldsymbol{P L} \boldsymbol{X})\end{array}$ & $\begin{array}{l}\text { Initiates interaction with conspecific in a non-harmful } \\
\text { manner (chasing, jumping, wrestling, etc.) and gets some }\end{array}$ \\
\hline
\end{tabular}


Played by conspecific ( $\boldsymbol{P L} \boldsymbol{X} \boldsymbol{p}$ ) Roll (RO)

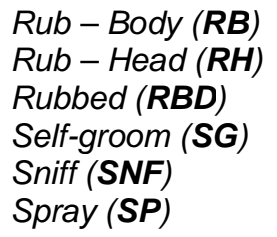

Walk (WK)

Run (RU)

Warning bite (W BT X)

Yawn $(\mathbf{Y N})$

Look Around (LOA)

Crouch (CR)

Crouch for other lion (CR $\boldsymbol{X})$

Dive in (DIN)

\section{Breeding behaviours}

Mount (MT)

Nape bite (N BT)

Being mounted (BM)

Sniff anogenital (SNA) response

Passive receiver of conspecific play

Lying on the ground, the animal rotates its body from side to side. During the roll, the back is rubbed against ground, the belly is exposed and all paws are in the air

Rubs body on conspecific or object

Rubs head on conspecific or object

Rubbed by a conspecific

Licks own fur

Smells by inhaling air through the nose

Stands with tail raised vertically and releases a jet of urine backwards against a vertical surface or object.

Usually slow, forward locomotion with back and head slightly lowered and eyes focused on the stalked individual/object.

Looks fixedly to something/someone

Tail is held vertically, in an upright position

Standing or moving with tail bent over body, slashing.

Prolonged, repeated movement of tip of the tail.

A rapid flick of the tail in either a side to side or up to down motion

Releases urine, standing or squatting

Produces sounds or calls with is mouth/throat

Cat expels jets of air through the nose creating a low-

intensity, soft, pulsed sound, described as being similar to the snorting of a horse

Short, throaty call, characterized by the deep contraction and expansion of the diaphragm

A low-pitched, throaty, rumbling noise produced while the mouth is closed.

A drawn-out, low-intensity hissing sound produced by rapid expulsion of air from the cat's mouth, usually during exhalation.

Long, throaty, high intensity call

Amiable call with the purpose of gather or appease conspecifics

Forward locomotion at a slow gait

Forward locomotion at a quick gait

Snap teeth in response to an unwelcomed closing individual.

The mouth is opened widely, the head tips back, lips are pulled back so that the teeth are exposed

Turn one's eyes toward something or in some direction in order to see

Bend close to the ground or stoop low for lay down

Stoop low and lays down on the sternum with ears backwards, head down or open mouth for submit to someone

Plunge into water and stay in the water

Moves on top of conspecific in the attempt of copulate The male performs an inhibited nape bite, where he will place his mouth on or around the back of the female's neck at the moment of, or just after, ejaculation, but is unlikely to actually bite down.

Is mounted by other tiger Smells the anogenital region of conspecific 
Table 3. Behavioral classes used to create time budgets. Individual behaviors come from the full ethogram, included in Table 2

\begin{tabular}{ll}
\hline Class & Behaviors included \\
\hline Inactive & Lie, sit, stand, stretch, stare \\
Locomotion & Walk, run, stalk, chase, climb, crouch \\
Stereotypic & Pace \\
Reproductive & Mount, sniff anogenital region, lordosis \\
Maintenance & Defecate, urinate, self-groom, scratch \\
Marking & Spray, scratch object \\
Vocalizations & Growl, grunt, roar, cough \\
Feeding & Eat, drink \\
Exploratory & Any interaction with objects, sniff, flehmen, dig \\
Interactions & Allogroom conspecific, bite conspecific, play with conspecific, chase conspecific, \\
& stalk conspecific, swat conspecific, head/body rub conspecific, tail up, band on glass \\
\hline
\end{tabular}

\section{$\underline{\text { 2.2.2 Internal enclosures }}$}

Animal behaviors were also observed and filmed in the indoor environments of their enclosures; areas where they are out of public sight, but come in close contact with the keepers. The observations in the enclosure internal area took place in the morning, before the opening to the public, and in the evening after the closing of the park, at the time of administration of the meal. Animal behaviour observations were performed by continuous recording of the entire group present during interaction with the keeper, recalling that the eight tigers lived into three different enclosures. For each of the 3 keepers, keeper-animal interactions were observed for 7 sessions.

In order to evaluate each animal interaction with the keeper, we analysed the number of affiliative (head rubbing, body rubbing), aggressive (hissing, snarling, barring teeth, roaring) and fearful (ears backward, moving away) behaviour events displayed during the sessions. Distance between the keeper and the tiger (contact, body length, far) was also recorded. The distance kept by animals to the keepers was used to calculate the Association Index between each animal and the three different keepers.

\subsubsection{Enclosure usage and spread of participation index (SPI)}

Each animal's enclosure usage was determined by processing data gathered during focal observations. The enclosures were arbitrarily divided into zones (Fig. $1 \mathrm{~A}, \mathrm{~B}, \mathrm{C}$ ), to distinguish areas that may be used for different purposes. The enclosure and each zone area size were calculated using Google Maps "Area Calculator Tool". These zones were assigned so that an animal's specific location could be recorded during each observation, which was used to determine each tiger's enclosure use for each observation period. The spread of participation index (SPI) was calculated to determine evenness of enclosure use. SPI was developed as previously described [15] to allow for zones of unequal areas. Possible SPI values range from 0 (even use of the enclosure) to 1 (uneven use of the enclosure).

\subsubsection{Association index}

In order to evaluate the strength of relationships between individuals, we calculated the Association index values (AI) for each relationship, as used by Schaller [30] and described elsewere [15]. This data considers the time that each animal spends in proximity of another tiger (i.e., at body-length or nearer). Possible Al values range from 0 (never seen in proximity) to 1 (always seen in proximity).

\subsection{Personality Profiles}

Personality profiles were compiled using questionnaires completed by three Le Cornelle keepers. The methodology for these questionnaires was adapted from Chadwick's research on cheetah personality, as previously described [6,31]. Questionnaires listed 31 traits, which were rated on a scale of 1 (trait was never exhibited) to 12 (trait was always exhibited) by the keepers for each tiger.

Behaviours recorded during observations were coded similarly to time budgets, such that classes could be compared to some of the traits on the personality questionnaire (Table 4). Behavioural classes followed those used in similar studies [15,7]. Profiles created from questionnaires were compared with profiles 
compiled from observation data. Not all traits were comparable between profiles because only behaviours representing some traits were observed during this study. The correlation index Spearman's rank-order correlation coefficient (rs) was used to validate the data obtained from the researcher's observations with those derived from the personality questionnaires compiled by the keepers. All values greater than $r s=0.4$ were considered reliable [7].

\subsection{Statistical Analysis and Data Presentation}

Data analysis was completed using Microsoft Excel 2013 and IBM Statistical Package for the Social Sciences. Due to a small sample size, most tests for statistical significance were deemed inappropriate and therefore analysis focuses on descriptive statistics. Inter-rater reliability was calculated for the personality questionnaires using intraclass correlation ICC $(3, k)$ for the reliability of the mean ratings of the raters. The association between activity and number of visitors, and for affiliative behavior and number of visitors was calculated by the Spearman non-parametric correlation test. Statistical significance was set to $p=.05$.

\section{RESULTS}

\subsection{Activity Budgets}

The tigers' activity budgets were calculated for the observation period. These were also combined to create an overall time budget for all observations. The charts, including data values, are displayed in Figs. 2-3. The chart in Fig. 2 shows the overall time budget for the observation period (all tigers combined), in Table 4 are summarized the standard deviation values between the behavioural categories of the observed individuals, while Fig. 3 shows activity budgets for each tiger.

The data showed a consistency of behaviour within the pride with some differences between individuals. Some individual differences were spotted in activity rates; in general, observed tigers spend most of their time moving or resting. The young Sky has been observed in movement most of the time (40\%), and was inactive considerably less than the rest of the group $(19 \% ; \delta=-2.09 ; p=.05)$. On the contrary, Giulietta was observed most often resting (37\%) and, compared to the other animals observed, in movement less often (24\%; $\delta=-2.31 ; p=.05)$.

Time spent during maintenance or feeding behaviours showed only slight quantitative differences between animals. As evidenced by Fig. 3, Kuru was the one who had the largest number of stereotyped behaviours, Romeo's observation results in the greatest number of reproductive behaviors $(\delta=2.35 ; p=.05)$, while Dharma was the most out of sight tiger $(\delta=2.32$; $\mathrm{p}=.05)$.

To find out if the age of the animals could have influenced some behavioural categories, age was related to animal activity. The analysis

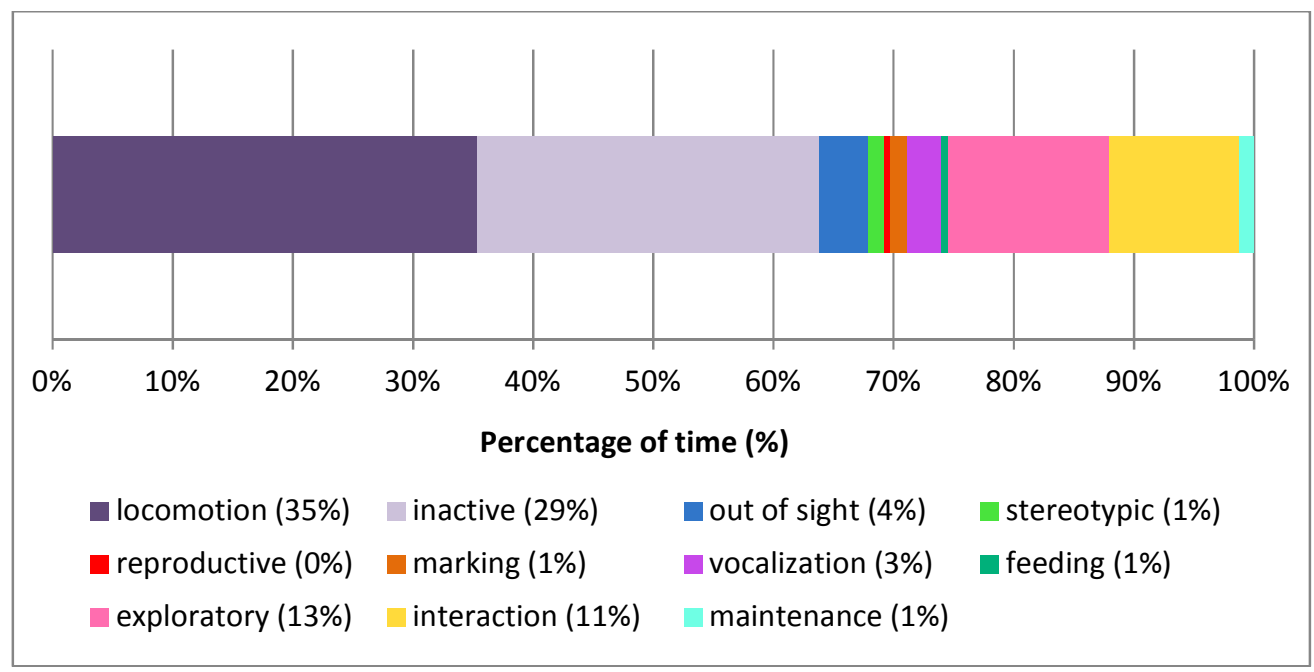

Fig. 2. Overall complete time budgets for the observation period. Data values are included to show exact percentages of time for each behaviour class 
Table 4. Standard deviation values between the behavioral categories of the observed individuals

\begin{tabular}{lllllllll}
\hline & Dharma & Kira & Sky & Kuru & Romeo & Giulietta & Obelix & Burma \\
\hline Locomotion & $-0,37$ & $-0,33$ & 1,06 & 0,25 & 0,52 & $-2,31$ & 0,96 & 0,22 \\
Inactive & $-0,38$ & 0,07 & $-2,09$ & $-0,11$ & $-0,43$ & 1,46 & 0,58 & 0,90 \\
Out of sight & 2,32 & $-0,03$ & $-0,55$ & $-0,18$ & $-0,55$ & 0,71 & $-0,89$ & $-0,83$ \\
Stereotypic & 0,96 & 0,76 & $-0,77$ & 1,94 & $-0,79$ & $-0,79$ & $-0,58$ & $-0,74$ \\
Reproductive & $-0,66$ & $-0,66$ & $-0,66$ & $-0,66$ & 2,35 & 0,79 & $-0,25$ & $-0,26$ \\
Marking & $-0,69$ & $-1,01$ & $-0,44$ & 1,74 & $-0,56$ & 0,32 & $-0,84$ & 1,47 \\
Vocalization & $-0,27$ & $-0,62$ & $-0,90$ & 0,32 & 1,44 & 1,75 & $-0,85$ & $-0,88$ \\
Feeding & 0,33 & 0,88 & 1,23 & $-1,59$ & $-1,44$ & $-0,41$ & 0,92 & 0,07 \\
Exploratory & $-1,15$ & $-0,59$ & 1,50 & 0,49 & $-0,77$ & $-1,16$ & 1,34 & 0,34 \\
Interaction & 0,60 & 1,33 & 0,82 & $-1,74$ & 0,38 & 0,42 & $-1,23$ & $-0,58$ \\
Maintenance & 1,51 & $-0,82$ & $-1,26$ & 1,22 & $-0,36$ & 0,60 & $-1,19$ & 0,30 \\
\hline
\end{tabular}

showed a moderate correlation between the age of the tigers and the time spent on the move; the activity of animals decreased on the basis of age $(\rho=-0,424)$.

In addition, the number of visitors around the enclosure was considered and whether it would affect the activity of the tigers. The correlation between individual activities and numbers of visitors present showed discordant values according to the tiger considered. Giulietta has a remarkable positive correlation between her activity and the number of visitors present ( $\rho=$ 0.922 ), so she tends to be more active in the presence of more visitors. On the contrary Kira has a strong negative correlation $(\rho=-0,814)$, indicating that the more people were present, the less she tended to be active (Table 5). As for the other individuals, the analysis revealed that Burma and Dharma showed a strong positive correlation $(\rho B=0.0737 ; \rho D=-0.0771)$, Kuru has a moderate positive correlation $(\rho \mathrm{Ku}=$ 0.423 ), Sky and Obelix have a poor negative correlation $(\rho S=-0.228 ; \rho O=-0.278)$, and finally Romeo has a poor positive correlation $(\rho R=$ 0.365 ) to the number of visitors present.
Regarding the time spent on affiliated or aggressive behaviours, a moderate positive correlation was found between the time spent on affiliated behaviours and the age of the animals: the more the age increases the more the animal tends to be less aggressive and more friendly (Fig. 4).

The animals showed an increase in affiliative behaviours as the number of visitors increased. Burma, Kira and Sky had a positive correlation between the number of visitors and their affiliative behaviours $(\rho B=0.831 ; \rho S=0.987$; $\rho \mathrm{Ki}=0.837)$; Obelix and Kuru a moderate positive correlation ( $\rho \mathrm{Ku}=0.477 ; \rho \mathrm{O}=0.590$ ); instead Giulietta and Dharma showed a moderate negative correlation $(\rho D=-0.687 ; \rho G$ $=-0.453$ ) indicating that with the increase of visitors they tended to be more aggressive; as well as Romeo, though with a poor correlation $(\rho R=-0.355)$.

\subsection{Association Index}

Following the method reported by Schaller [30], the tigers were divided into 5 groups to highlight

Table 5. Percentage of time when the animals were observed active in relation to the number of visitors present. vis indicates visitors

\begin{tabular}{llllll}
\hline Subject & $\mathbf{0}$ vis & $\mathbf{1 - 1 0}$ vis & $\mathbf{1 1 - 2 0}$ vis & $\mathbf{2 1 - 3 0}$ vis & $\mathbf{3}$ 30 vis \\
\hline DHARMA & $45 \%$ & $20 \%$ & $13 \%$ & $34 \%$ & $39 \%$ \\
KIRA & $41 \%$ & $24 \%$ & $27 \%$ & $0 \%$ & $9 \%$ \\
SKY & $46 \%$ & $42 \%$ & $31 \%$ & $45 \%$ & $/$ \\
KURU & $68 \%$ & $33 \%$ & $34 \%$ & $35 \%$ & $35 \%$ \\
ROMEO & $46 \%$ & $27 \%$ & $27 \%$ & $56 \%$ & $41 \%$ \\
GIULIETTA & $26 \%$ & $17 \%$ & $24 \%$ & $41 \%$ & $57 \%$ \\
OBELIX & $40 \%$ & $25 \%$ & $15 \%$ & $28 \%$ & $27 \%$ \\
BURMA & $39 \%$ & $29 \%$ & $44 \%$ & $43 \%$ & $31 \%$ \\
\hline
\end{tabular}




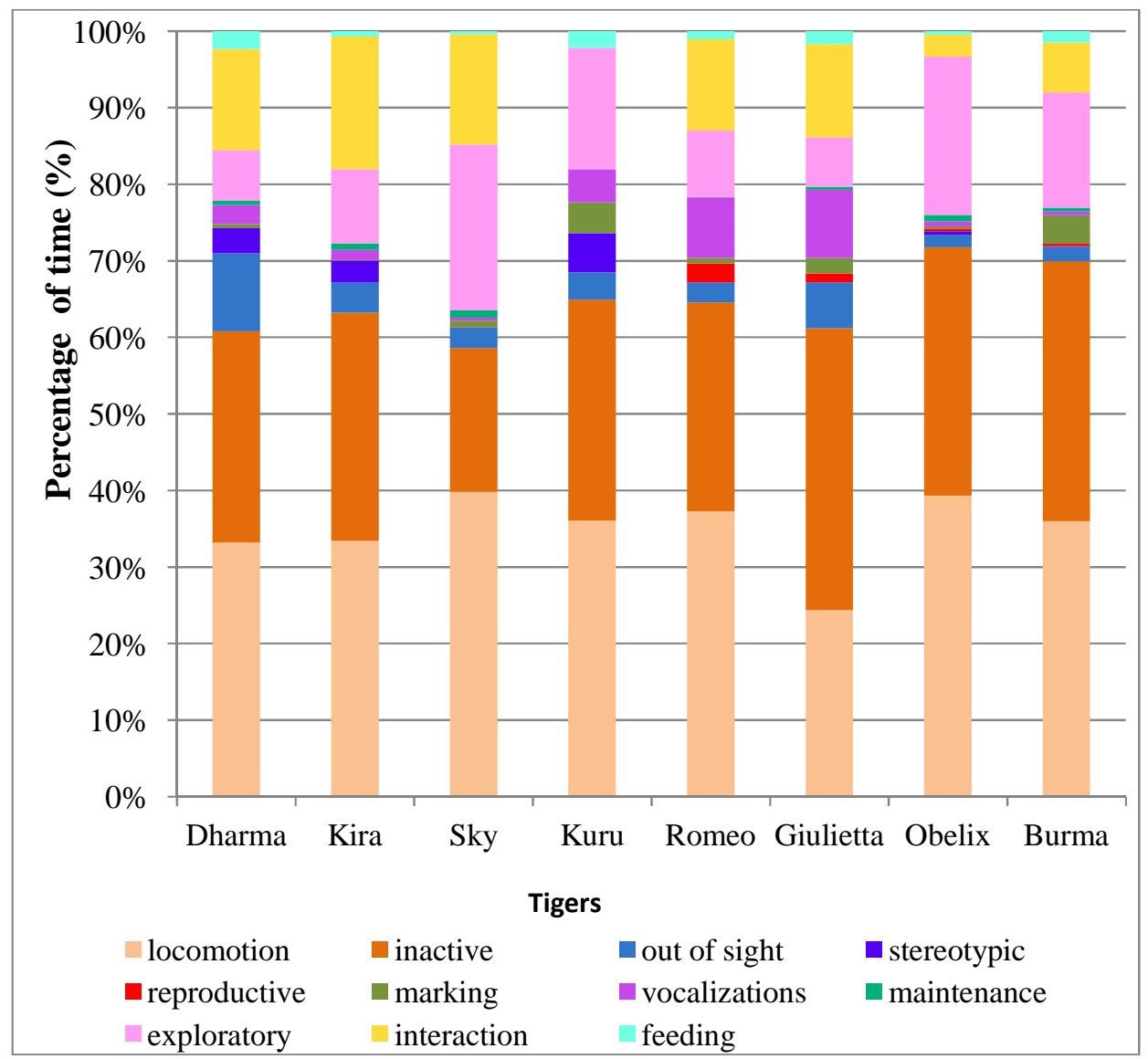

Fig. 3. Activity budgets for each tiger. Data values are expressed as percentages of time for each behaviour class

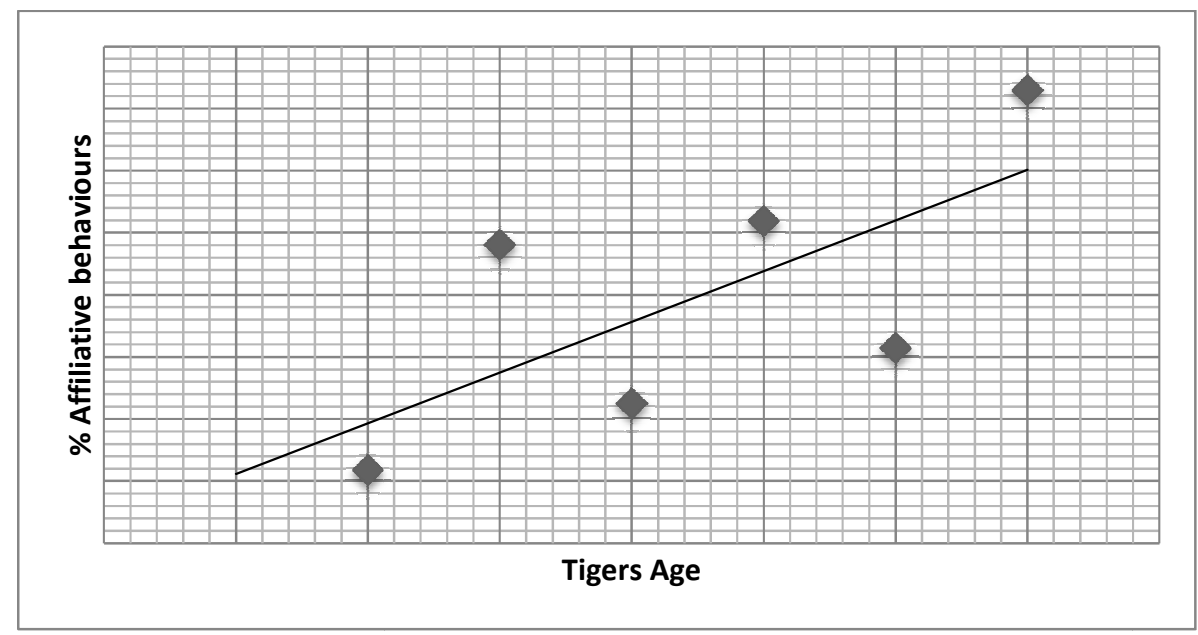

Fig. 4. Graph of the dispersion tigers age - affiliative behaviours

dyadic relationships between individuals sharing the enclosure. The association index was calculated by evaluating the affinity between
Burma-Obelix and Juliet-Romeo and the affinity between Dharma, Kira and Sky. 
The data analysis shows that the strongest relationship is between Kira and Dharma ( $\left.A I_{D K}=0,443 ; A I_{K D}=0,484\right)$, followed by the association between Kira and Sky ( $A I_{K S}=$ 0,$\left.419 ; A I_{S K}=0,398\right)$. The dyad with the lowest index is that of Obelix and Burma ( $A I_{O B}=$ 0,$05 ; A I_{B O}=0,05$ ) with values close to zero, pointing out that these two tigers were rarely observed close to each other.

\subsection{Spread of Participation Index}

Spread of participation index values are displayed, per animal, in Table 6. SPI values range from 0 to 1 , meaning 0 for even-use and 1 for completely uneven use of the enclosure.

The values for each tiger indicate a modest inhomogeneity for the use of areas in which the enclosures were divided. The preference for some zones at animal disposal can be due to several resources being located in these zones: i.e. the presence of shelters from the elements, provided by artificial structures, the availability of a source of water, the proximity to the building where the animals are managed and from where keepers arrive, the presence of high platforms, with good visibility all around, as well as feeding and enrichment delivery points [32].

Table 6. Spread of participation index, per animal. The spread participation index (SPI) with a scale of $0-1$, with 0 being even-usage and 1 being usage in one area

\begin{tabular}{lc}
\hline Subject & SPI value \\
\hline ROMEO & 0,12992 \\
GIULIETTA & 0,145911 \\
OBELIX & 0,101398 \\
BURMA & 0,102778 \\
DHARMA & 0,214485 \\
KIRA & 0,187574 \\
SKY & 0,156676 \\
KURU & 0,233022 \\
\hline \multicolumn{2}{c}{ Tiger-Keeper Association Index }
\end{tabular}

The association between individual tigers and the three keepers indicated that there was a strong relationship between Dharma, Sky, Kuru, and Keeper $1 \quad\left(K A I_{D 1}=0,716 ; K A I_{S 1}=0,884\right.$; $\left.K A I_{K U 1}=0,899\right)$. Keeper 2 and Dharma and Sky had also a strong association $\left(K A I_{D 2}=0,851\right.$; $\left.K A I_{S 2}=0,930\right)$ and a high association was found between Keeper 2 and Kuru $\left(K A I_{K U 2}=0,648\right)$.
In general, Giulietta was the tiger with less social affiliation with keepers $\left(K A I_{G}=0,091\right)$, followed by Kira $\left(K A I_{K}=0,139\right)$, Romeo $\left(K A I_{R}=0,195\right)$ and Burma $\left(K A I_{B}=0,211\right)$. In contrast, Dharma $\left(K A I_{B}=0,576\right)$, Kira $\left(K A I_{B}=0,703\right)$ and Kuru $\left(K A I_{B}=0,673\right)$ manifested the greatest social affiliation towards keepers, followed by Obelix $\left(K A I_{B}=0,310\right)$. Within the sleeping area, regardless of which keeper was present, Kuru showed more stereotypical behaviors in contact with keepers (25\%), followed by Burma (22\%). Romeo (0\%), Sky (1\%), Dharma (2\%), Juliet $(2 \%)$ and Obelix (5\%) showed lower values, while Kira was at an intermediate level (12\%).

\subsection{Personality Profiles}

Personality profiles are presented on one individual at a time. Each individual had a personality profile created using the observations (data not showed) and a profile created with the trait ratings (Fig. 5).

The correlation test of Spearman's ranks analysis evidenced that the ratings of the keepers and the behavioural observations values tend to be similar, except in the case of Kuru and Kira.

Specifically, Keeper 1 ratings agree with observational data of Romeo, Juliet and Obelix $\left(r s_{R 1}=0,573 ; r s_{G 1}=0,611 ; r s_{O 1}=0,536\right)$; Keeper 2 ratings with Dharma, Sky, Romeo, Juliet and Obelix observational data $\left(r s_{D 2}=\right.$ 0,$476 ; r s_{S 2}=0,432 ; r s_{R 2}=0,524 ; r s_{G 2}=$

0,$\left.475 ; r s_{O 2}=0,465\right)$ and Keeper 3 ratings with the data derived from the observation of Sky, Giulietta and Obelix $\left(r s_{S 3}=0,490 ; r s_{G 3}=\right.$ 0,$\left.440 ; r s_{O 3}=0,549\right)$.

In the present study, we evaluated whether animals exhibited stereotypical behavior (in form of anticipatory pacing) in the presence of keeper, and if there were any differences among the animals, depending on the keeper. For this purpose, we calculated the percentage of time during which the tigers manifested stereotyped behaviors, with respect to the total time of the observations in which the tigers are in contact with the keepers. The results showed that tigers exhibited more stereotyped behavior in the presence of Keeper 1 (11.3\%) while with the other two Keepers lower pacing values were observed (K2 4.37\%, K3 6.25\% respectively). 

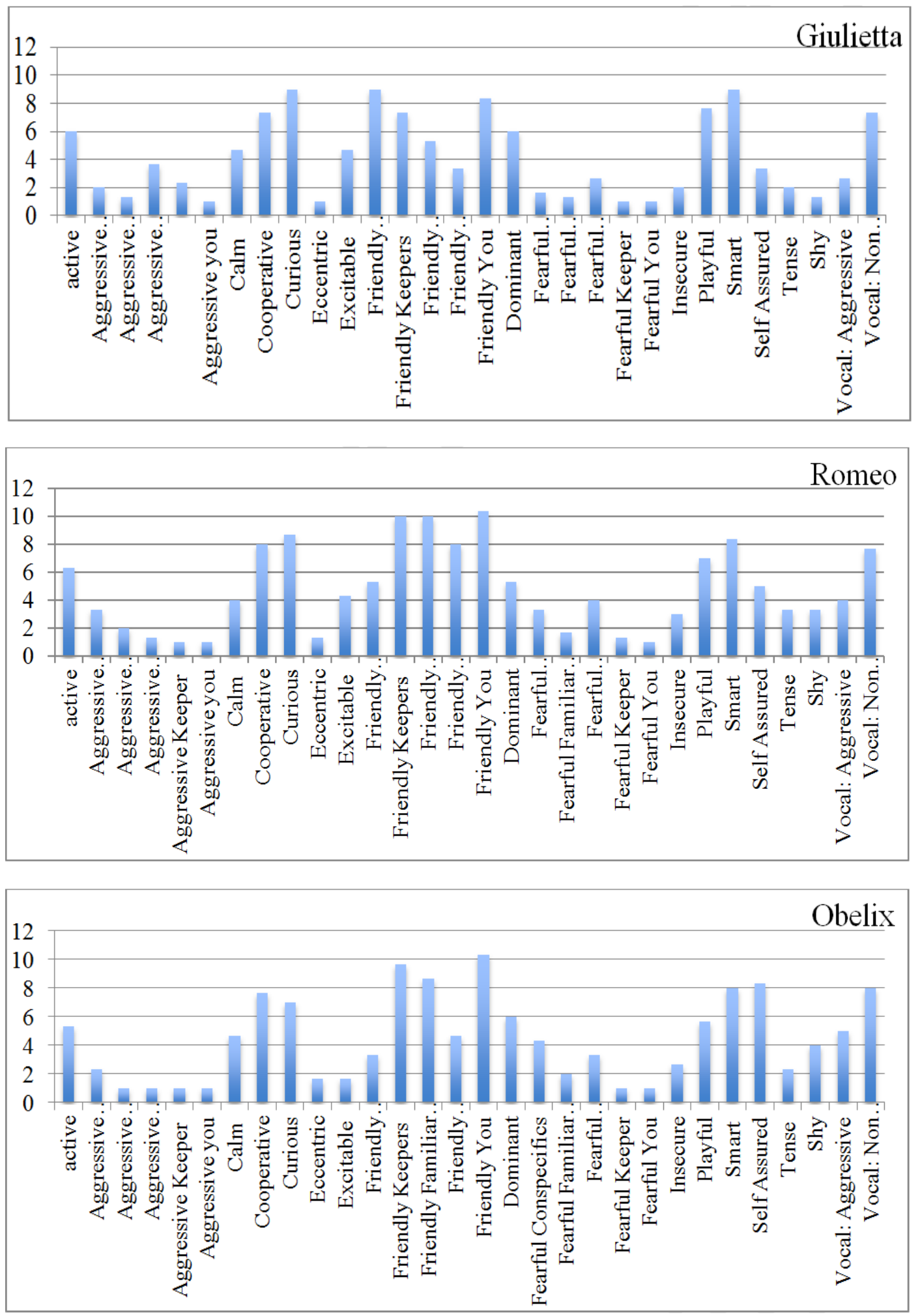

Fig. 5. Personality profiles of Romeo, Giulietta and Obelix. Profiles were created from the questionnaires 
Fig. 5 (Continues from the previous page)
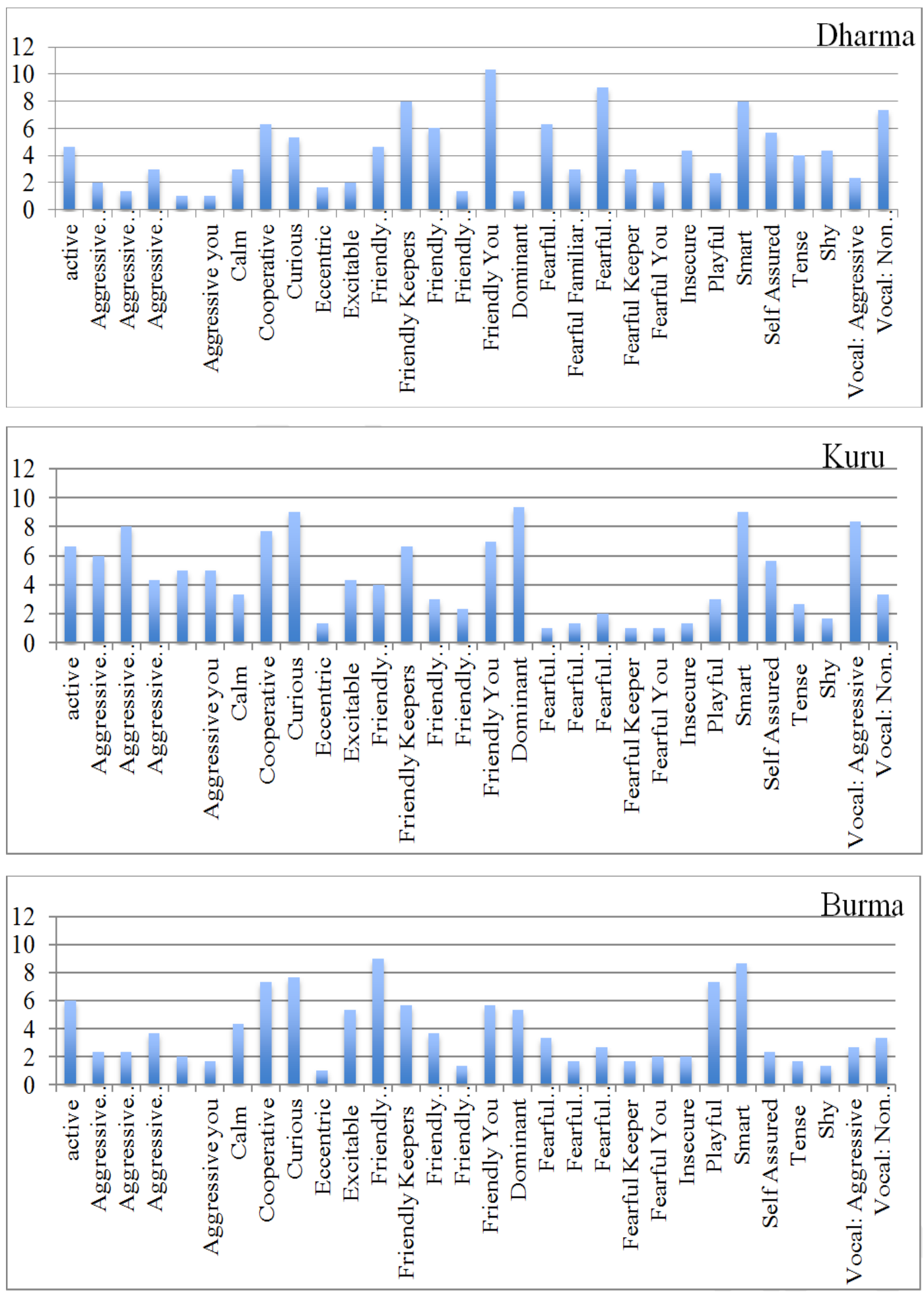

Fig. 5. Personality profiles of Dharma, Kuru and Burma. Profiles were created from the questionnaires 
Fig. 5 (Continues from the previous page)
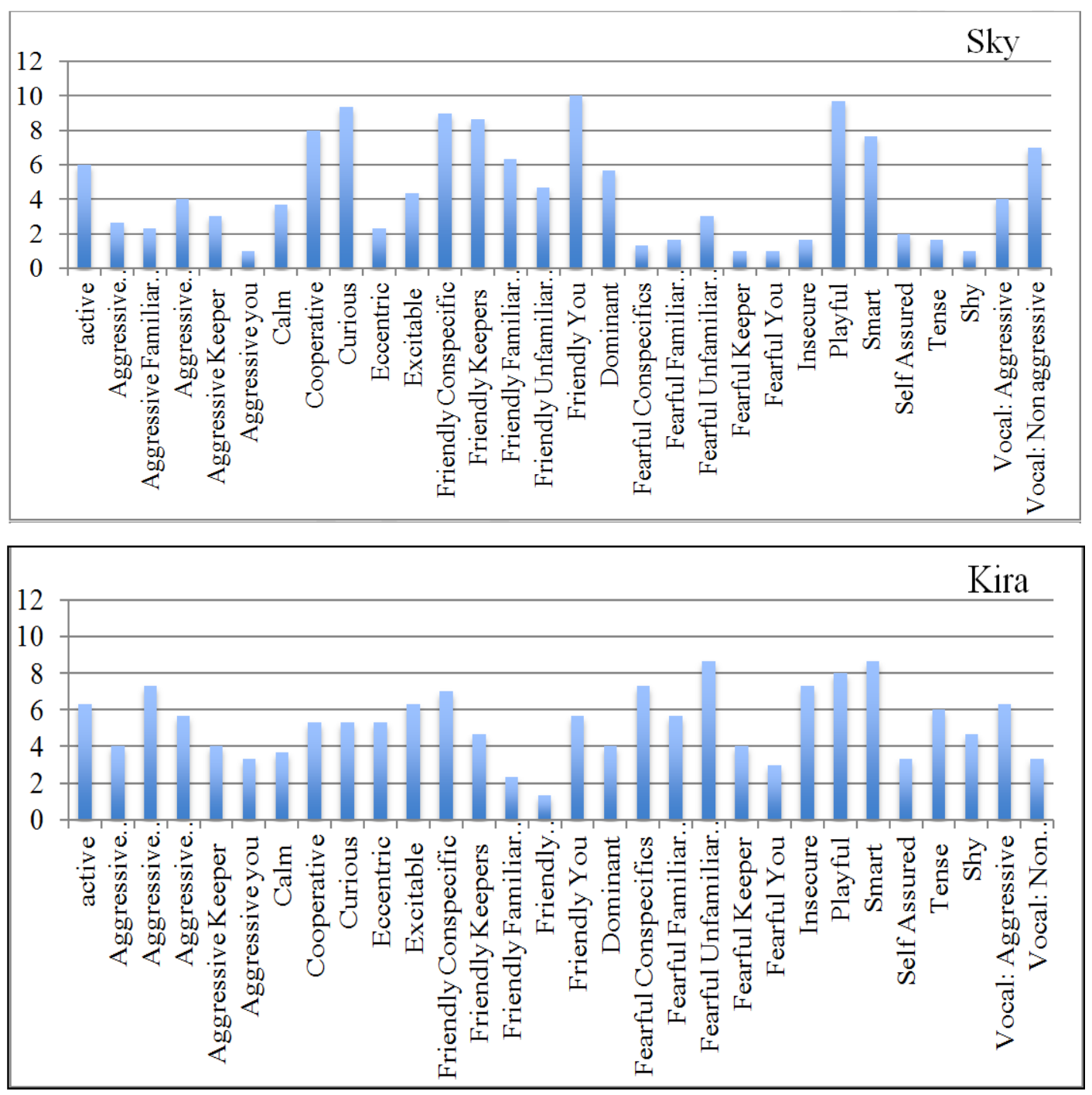

Fig. 5. Personality profiles of Sky and Kira. Profiles were created from the questionnaires

\section{DISCUSSION}

In the present study, we produced a personality profiles for each individual: these can be an excellent tool for understanding the level of activity and distinctive features of each tiger housed in the Le Cornelle Faunistic Park. This knowledge will certainly facilitate the management of these animals and help the design of specific enrichment activities for each individual, according to their personality profile and Spread of participation index value, maximizing the effectiveness of these programs and minimizing the stress of animals.
Currently, there are two methods used in the study of animal personality: the rating method and the coding method [13]. The rating method involves human observers making judgments about an individual animal's behavioral traits, while the coding method involves the assessments of an animal's behavior during naturally occurring activities [33]. Some researchers believe that the best way to study personality in animals is to employ a combination of both coding and rating techniques, in order to generate more information, thus increasing the validity and reliability of the measures [33]. 
In our study, we found a high level of consistency between the keepers in assessing the personality traits of individual tigers, while the correlation between profiles produced by the keepers' questionnaires and those from behavioural observations varies from tiger to tiger. This could be due, at least in part, to the different observation circumstances; behavioral observations took place throughout the day, when animals have the opportunity to express a large part of their behavioral repertoire. On the contrary, keepers often interact with animals only at certain times of the day, when routine activities can influence the behavior of animals, partly influencing their responses.

In the past decade research has shown that, in some species at least, personality can influence how animals interact in captive breeding situations. This makes sense, given the evidence that personality affects fitness in the wild across a number of species, with a clear connection between boldness and reproductive success (at the expense of survival, however) and between exploration and survival [34]. In the present study, the result emerged by comparing the two pair of tigers Romeo and Giulietta and Burma and Obelix are interesting. From the time budget analysis, Obelix and Burma, the couple who showed fewer reproductive behaviours and minor interactions, was also the one with the association index that tends to zero. This leads us to speculate that those couples who produce similar scores may be not recommended for a possible breeding program. It would be interesting to investigate the role of personality on their supposed incompatibility. From behavioural observations it has emerged that Giulietta is most dominant when confronted with Burma, but this may not be the only factor influencing their relationship with males. In fact, during the behavioural observation, both females showed the typical courtship behavior towards the male, to which the two males responded in the opposite way: Romeo, albeit submissive, responded with the mount, while Obelix prompted Burma to move away. In any case, the number of subjects in the study is too small to gather information about this aspect and it would be necessary to extend the study to other tiger pairs.

\section{CONCLUSION}

The analysis of the results obtained in this study has allowed the tracing of personality profiles that successfully characterize captive tigers. Keeper-animal interactions has proven to be a promising source of data for some social personality traits evaluation. Analytic tools like the association index and the spread participation index prove to be useful to access personality traits related with social aspects within the pride and the way the animal uses the enclosure. Overall, significant progress was made to develop an approach that can reliably access animal personality, plus impact their health and welfare through more customized management, which can better suit different individual needs.

Improvements can be made in these methodologies by increasing the number of animals observed, increasing the hours of observation, and through the installation of time lapse cameras that would allow gathering data from animal behaviour with special relevance to dusk and dawn; this would prove invaluable, not only by increasing the quantity of behaviours accessed but also by increasing the diversity of the same, improving the ability of successfully identify and characterize personality traits in the studied animals.

\section{ETHICAL CONSIDERATION}

This observational study did not require ethical approval.

\section{ACKNOWLEDGEMENTS}

This research received no specific grant from any funding agency in the public, commercial, or notfor-profit sectors.

The authors would like to thank Dr. Rainer Schneider and Dr. Davide Guadagnini whose cooperation has enabled the realization of the study.

A special thank you to all the zoo keepers at the Cornelle Faunistic Park for their collaboration and for filling in the questionnaires and providing information on the study animals and their management.

\section{COMPETING INTERESTS}

Authors have declared that no competing interests exist. 


\section{REFERENCES}

1. Pervin LA. Wiley: Personality: Theory and Research, $12^{\text {th }}$ Edition - Daniel Cervone, Lawrence A. Pervin. Accessed September $5,2017$.

Available:http://www.wiley.com/WileyCDA/ WileyTitle/productCd-EHEP002469.html

2. Kortet, Raine, Ann V. Hedrick, Anssi Vainikka. Parasitism, predation and the evolution of animal personalities. Ecology Letters. 2010;13(12):1449-58.

DOI:https://doi.org/10.1111/j.14610248.2010.01536.x.

3. Stanley, Christina R, Claudia MettkeHofmann, Richard F. Preziosi. Personality in the cockroach Diploptera punctata: evidence for stability across developmental stages despite age effects on boldness. PLOS ONE. 2017;12(5):e0176564.

DOI:https://doi.org/10.1371/journal.pone.0 176564.

4. Watters, Jason V, David M. Powell. Measuring animal personality for use in population management in zoos: Suggested methods and rationale. Zoo Biology. 2012;31(1):1-12.

DOI:https://doi.org/10.1002/zoo.20379.

5. Gartner, Marieke Cassia, Alexander Weiss. Personality in felids: A review. Applied Animal Behaviour Science. 2013a;144(1):1-13.

DOI:https://doi.org/10.1016/j.applanim.201

2.11.010.

6. Chadwick C. Social behaviour and personality assessment as a tool for improving the management of cheetahs (Acinonyx Jubatus) in captivity. Phd, University of Salford; 2014.

DOI:http://usir.salford.ac.uk/31793/

7. Gartner, Marieke Cassia, Weiss Alexander. Scottish Wildcat (Felis Silvestris Grampia) Personality and Subjective Well-Being: Implications for Captive Management. Applied Animal Behaviour Science, Welfare of Zoo Animals. 2013;147(3):261-67.

DOI:https://doi.org/10.1016/i.applanim.201 2.11.002.

8. Carter, Alecia J, William E. Feeney, Harry H. Marshall, Guy Cowlishaw, and Robert Heinsohn. Animal personality: What are behavioural ecologists measuring?" Biological Reviews. 2013;88(2):465-75. DOI:https://doi.org/10.1111/brv.12007

9. Réale, Denis, Simon M. Reader, Daniel Sol, Peter T. McDougall, Niels J.
Dingemanse. Integrating animal temperament within ecology and evolution. Biological Reviews. 2007;82(2):291-318. DOI:https://doi.org/10.1111/j.1469185X.2007.00010.x.

10. Sih, Andrew, Alison M. Bell, J. Chadwick Johnson, Robert E. Ziemba. Behavioral syndromes: An integrative overview. Quarterly Review of Biology. 2004;79(3): 241-77.

DOI:https://doi.org/10.1086/422893

11. Meagher RK. Observer ratings: Validity and value as a tool for animal welfare research. Applied Animal Behaviour Science. 2009;119(1/2):1-14.

12. Freeman, Hani D, Samuel D. Gosling. Personality in nonhuman primates: A review and evaluation of past research. American Journal of Primatology. 2010;72(8):653-71.

DOI:https://doi.org/10.1002/ajp.20833.

13. Highfill, Lauren, David Hanbury, Rachel Kristiansen, Stan Kuczaj, Sheree Watson. Rating vs. coding in animal personality research. Zoo Biology. 2010;29(4):509-16. DOI:https://doi.org/10.1002/zoo.20279.

14. Birgersson Sabina. Personality assessment and interactions in eight captive bottlenose dolphins (Tursiops Truncatus); 2011.

DOI:https://core.ac.uk/display/41212627.

15. Quintavalle Pastorino, Giovanni, Viau Anna, Curone Giulio, Pearce-Kelly Paul, Faustini Massimo, Vigo Daniele, Mazzola Silvia Michela, Preziosi Richard. Role of Personality in Behavioral Responses to New Environments in Captive Asiatic Lions (Panthera Leo Persica). Veterinary Medicine International; 2017.

DOI:https://doi.org/10.1155/2017/6585380.

16. Rees PA. Studying captive animals: A workbook of methods in behaviour, welfare and ecology. John Wiley \& Sons; 2015.

17. Cinková, Ivana, Vítězslav Bičík. Social and reproductive behaviour of critically endangered northern white rhinoceros in a zoological garden." Mammalian Biology Zeitschrift Für Säugetierkunde. 2013;78(1): 50-54.

DOI:https://doi.org/10.1016/j.mambio.2012 .09 .007$.

18. Micheletta, Jérôme, Bridget $M$. Waller. Friendship affects gaze following in a tolerant species of macaque, Macaca Nigra. Animal Behaviour. 2012;83(2):45967. 
DOI:https://doi.org/10.1016/..anbehav.2011 .11.018.

19. Pullen, Penelope Kirsten. Male-Male social interactions in breeder and bachelor groups of gorillas (Gorilla Gorilla): An Indication of Behavioural Flexibility; 2009. https://ore.exeter.ac.uk/repository/handle/1 0036/89273.

20. Dickens M. A statistical formula to quantify the spread of participation in group discussion. Speech Mon. 1955;22:28-31.

21. Plowman $A B$. A note on a modification of the spread of participation index allowing for unequal zones. Applied Animal Behaviour Science. 2003;83(4):331-36. DOI:https://doi.org/10.1016/S01681591(03)00142-4.

22. Wielebnowski NC. Behavioral differences as predictors of breeding status in captive cheetahs. Zoo Biol. 1999;18(4):335-349.

23. Hosey, Geoff, Vicky Melfi. Human-animal interactions, relationships and bonds: $A$ review and analysis of the literature. International Journal of Comparative Psychology. 2014;27(1).

http://escholarship.org/uc/item/6955n8kd.

24. Kreger, Michael D, Joy A. Mench. Visitoranimal interactions at the zoo. Anthrozoös. 1995;8(3):143-58.

DOI:https://doi.org/10.2752/089279395787 156301.

25. Cassini, Marcelo H. Behavioural responses of South American fur seals to approach by tourists - a brief report. Applied Animal Behaviour Science. 2001;71(4):341-46. DOI:https://doi.org/10.1016/S01681591(00)00205-7.

26. Hosey, Geoff. A preliminary model of human-Animal relationships in the zoo. Applied Animal Behaviour Science. 2008;109(2):105-27.

DOI:https://doi.org/10.1016/i.applanim.200 7.04.013.
27. Hosey, Geoff, Vicky Melfi. Human-Animal bonds between zoo professionals and the animals in their care. Zoo Biology. 2012;31(1):13-26.

DOI:https://doi.org/10.1002/zoo.20359.

28. Hosey, Geoff, Vicky Melf. Are we ignoring neutral and negative human-animal relationships in zoos? Zoo Biology. 2015;34(1):1-8.

DOI:https://doi.org/10.1002/zoo.21182.

29. Martin P, Bateson P. Measuring behaviour: An introductory guide. 3rd ed.: Cambridge University Press; 2007.

30. Schaller GB. The serengeti lion: A study of predator-prey relations. University of Chicago Press; 1972.

31. Quintavalle Pastorino, Giovanni, Yiannis Christodoulides, Giulio Curone, Paul Pearce-Kelly, Massimo Faustini, Mariangela Albertini, Richard Preziosi, Silvia Michela Mazzola. Behavioural Profiles of Brown and Sloth Bears in Captivity. Animals. 2017;7(5):39.

DOI:https://doi.org/10.3390/ani7050039

32. Rose P, Robert R. Evaluating the activity patterns and enclosure usage of a littlestudied zoo species, the sitatunga (Tragelaphus spekii). Journal of Zoo and Aquarium Research. 2013;1(1):14-9.

33. Vazire S, Gosling SD. Personality and temperament: A comparative perspective. In: Bekoff $\mathrm{M}$, editor. Encyclopedia of Animal Behavior. Westport, CT: Greenwood Publishing Group. 2004;818822.

34. Smith, Brian R, Daniel T. Blumstein. Fitness consequences of personality: $A$ meta-analysis. Behavioral Ecology. 2008; 19(2):448-55.

DOI:https://doi.org/10.1093/beheco/arm14 $\underline{4 .}$

(c) 2017 Pastorino et al.; This is an Open Access article distributed under the terms of the Creative Commons Attribution License (http://creativecommons.org/licenses/by/4.0), which permits unrestricted use, distribution, and reproduction in any medium, provided the original work is properly cited.

Peer-review history:

The peer review history for this paper can be accessed here: http://sciencedomain.org/review-history/22359 